\title{
Monitoramento estrutural em obras viárias utilizando a técnica RTK/NTRIP: Análise dos dados, desenvolvimento e implementação de um sistema de alerta posicional
}

Structural monitoring in road works using the RTK / NTRIP technique: Data analysis, development and implementation of a positional alert system

Monitoreo estructural en obras viales mediante la técnica RTK / NTRIP: Análisis de datos, desarrollo e implementación de un sistema de alerta posicional

Recebido: 05/06/2021 | Revisado: 10/06/2021 | Aceito: 16/06/2021 | Publicado: 04/07/2021

Fabiane de Fátima Maciel

ORCID: https://orcid.org/0000-0002-7117-6965 Instituto Federal de Educação, Ciência e Tecnologia do Sudeste de Minas Gerais, Brasil E-mail: fabiane.maciel@ifsudestemg.edu.br

Hérida dos Reis Silva

ORCID: https://orcid.org/0000-0002-8783-9604 Instituto Federal de Educação, Ciência e Tecnologia do Sul de Minas Gerais, Brasil E-mail: herida.mg@gmail.com

Fabio Luiz Albarici

ORCID: https://orcid.org/0000-0003-4436-0561 Instituto Federal de Educação, Ciência e Tecnologia do Sul de Minas Gerais, Brasil E-mail: fabio.albarici@ifsuldeminas.edu.br

Luciano Aparecido Barbosa ORCID: https://orcid.org/0000-0001-7973-0708 Instituto Federal de Educação, Ciência e Tecnologia do Sul de Minas Gerais, Brasil E-mail: luciano.barbosa@ifsuldeminas.edu.br

Jorge Luiz Alves Trabanco

ORCID: https://orcid.org/0000-0002-2558-2858

Universidade Estadual de Campinas, Brasil

E-mail: trabanco@fec.unicamp.br

\begin{abstract}
Resumo
Desde a ampliação do sistema rodoviário no Brasil na década de 1930, tem-se um cenário com inúmeras obras viárias em diferentes condições de uso e segurança. Tal fato é preocupante devido à falta de monitoramento adequado em OAEs (Obras de Arte Especiais) e por quem de fato estas estruturas devem ser monitoradas. Estas estruturas estão sujeitas às ações de forças estáticas e dinâmicas, podendo causar deslocamentos e/ou deformações que se caracterizam por sua amplitude, direção e comportamento temporal. Há também processos de deteriorações, sejam por desgaste ao uso ou por solicitações naturais, levando-se ao enfraquecimento da estrutura. A incorporação de métodos de inspeção e monitoramento no comportamento estrutural em OAEs torna-se crescente devido ao alto custo de recuperação destas obras. Contudo, é necessário que haja um plano de monitoramento contínuo ou periódico, de acordo com as grandezas admissíveis de cada estrutura. A tecnologia dos GNSS (Global Navigation Satellite Systems) por meio da metodologia de levantamento RTK (Real Time Kinematic), mostrou-se capaz de oferecer suporte em tempo real no controle de deformações estruturais. Neste contexto, foi desenvolvido o SiGE (Sistema de Gerenciamento Estrutural) para monitoramento e emissão de alertas acerca de eventos previamente determinados pelo operador do sistema. Com a obtenção destes dados em tempo real, é possível avaliar a segurança da estrutura em serviço, monitorar a estrutura de forma contínua e segura e aprimorar projetos futuros com a definição de deslocamentos estruturais máximos.
\end{abstract}

Palavras-chave: Transportes; Estrutura; OAEs; GNSS; SiGE.

\begin{abstract}
Since the expansion of the highway system in Brazil in the 1930s, there has been a scenario with numerous road works in different conditions of use and safety. This fact is worrying due to the lack of adequate monitoring in OAEs (Special Works of Art) and by whom in fact these structures must be monitored. These structures are subject to the actions of static and dynamic forces, which can cause displacements and / or deformations that are characterized by their amplitude, direction and temporal behavior. There are also deterioration processes, whether due to wear and tear or natural stresses, leading to the weakening of the structure. The incorporation of inspection and monitoring methods in the structural behavior in OAEs is increasing due to the high cost of recovery of these works. However, it is necessary to have a continuous or periodic monitoring plan, according to the permissible quantities of each structure. The technology of GNSS (Global Navigation Satellite Systems) through the methodology of survey RTK (Real Time
\end{abstract}


Kinematic), was able to offer support in real time in the control of structural deformations. In this context, SiGE (Structural Management System) was developed for monitoring and issuing alerts about events previously determined by the system operator. By obtaining this data in real time, it is possible to evaluate the safety of the structure in service, monitor the structure continuously and safely and improve future projects with the definition of maximum structural displacements.

Keywords: Transport; Structure; OAEs; GNSS; SiGE.

\section{Resumen}

Desde la expansión del sistema vial en Brasil en la década de 1930, ha existido un escenario con numerosas obras viales en diferentes condiciones de uso y seguridad. Este hecho es preocupante debido a la falta de un seguimiento adecuado en las OAEs (Obras de Arte Especiales) y por quién de hecho estas estructuras deben ser monitoreadas. Estas estructuras están sujetas a la acción de fuerzas estáticas y dinámicas, que pueden provocar desplazamientos y / o deformaciones que se caracterizan por su amplitud, dirección y comportamiento temporal. También existen procesos de deterioro, ya sea por desgaste o por tensiones naturales, que conducen al debilitamiento de la estructura. La incorporación de métodos de inspección y seguimiento en el comportamiento estructural en OAEs está aumentando debido al alto costo de recuperación de estas obras. Sin embargo, es necesario contar con un plan de seguimiento continuo o periódico, de acuerdo con las cantidades permisibles de cada estructura. La tecnología de GNSS (Global Navigation Satellite Systems) a través de la metodología de levantamiento $R T K$ (Real Time Kinematic), fue capaz de ofrecer soporte en tiempo real en el control de deformaciones estructurales. En este contexto, se desarrolló SiGE (Structural Management System) para monitorear y emitir alertas sobre eventos previamente determinados por el operador del sistema. Al obtener estos datos en tiempo real, es posible evaluar la seguridad de la estructura en servicio, monitorear la estructura de manera continua y segura y mejorar los proyectos futuros con la definición de los desplazamientos estructurales máximos.

Palabras clave: Transporte; Estructura; OAE; GNSS; SiGE.

\section{Introdução}

Tão importante como construir é manter as estradas e seus elementos constituintes em condições de funcionamento. De forma geral, estruturas viárias apontam uma especial tratativa as OAEs (Obras de Arte Especiais) denominadas como estruturas de pontes, viadutos e túneis (Timerman, 2018). Em 2012, o TCU (Tribunal de Contas da União) publicou relatório (TC 009.746/2012-9) constatando que o DNIT (Departamento Nacional de Infraestrutura de Transportes) não possui informações sobre a situação de pontes e viadutos em todo país e que não há um programa para prevenir patologias ou para antecipar colapsos em OAEs e, por isso, agem apenas em danos estruturais graves. O órgão chegou a criar o SGO (Sistema de Gerenciamento Informatizado de Obras de Arte Especiais) e exigiu a manutenção dos dados de todas as inspeções. Neste mesmo documento havia a constatação de que, desde 2004, o banco de dados do SGO não era fomentado pelo DNIT.

O DNIT (2015) declarou que ao todo, é responsável pela gestão de 5114 OAEs e que as inspeções são rotineiras. Deste total, $4020(78,6 \%)$ receberam as visitas de técnicos e que as rodovias apresentavam ótimas condições. Esta foi a última publicação do DNIT sobre inspeções em OAEs em seu site. Atualmente, não há nenhuma informação referente ao monitoramento utilizando o SGO. Contudo, as informações relatadas pelo SGO-Web podem não ser aplicadas ou não liberadas ao acesso público para consulta.

Timerman (2018), questionou o número de pontes e viadutos rodoviários existentes nas estradas brasileiras. Segundo ele, os órgãos DNIT e DER (Departamento de Estradas de Rodagem) não sabem os valores exatos referentes a OAEs existentes. No entanto, afirmou que devido ao seu trabalho de inspeção em pontes, permitiu-se fazer um catálogo particular que estima existirem cerca de 120 mil pontes e viadutos nas rodovias que cruzam o país. Relatou ainda que 9 mil destas OAEs estariam sob os cuidados de concessionárias, quanto às demais, não há registros de manutenção firmados pelo DNIT ou DER.

No Brasil, há normas e manuais publicados por entidades nacionais como a ABNT 9452 (2016): Inspeção de pontes, viadutos e passarelas de concreto - Procedimento; DNIT (2004): Manual de inspeção de pontes rodoviárias; DNIT (2010): Manual de recuperação de pontes e viadutos rodoviários; DNIT (2016): Manual de manutenção de Obras de Arte Especiais OAEs. 
Baseando-se na norma ABNT 9452 (2016), as inspeções são divididas em: Cadastral, Rotineira, Especial e Extraordinária. Nas inspeções Cadastral e Rotineira são utilizadas apenas recursos cadastrais (formulários) e registros fotográficos que ilustram a situação atual da estrutura, sendo que a inspeção rotineira ocorre a cada dois anos. Logo, é possível identificar que estas inspeções são basicamente visuais, não levando-se em conta o comportamento da estrutura em uso. As anomalias das estruturas são levadas em consideração a partir da inspeção especial, realizada a cada cinco anos, com a execução de ensaios laboratoriais mais conclusivos. A inspeção extraordinária é realizada quando há uma ocorrência de impacto, como desestabilização da estrutura por desgaste ao uso ou por causas naturais (inundações, eventos sismos etc.), sendo esta uma inspeção mais específica. O DNIT inseriu ao manual de inspeção de pontes rodoviárias (2004) a inspeção Intermediária, realizada quando recomendado por inspeções anteriores. As OAEs também são avaliadas de acordo com seus paramentos estruturais, funcionais e durabilidade que por fim atribuem a uma nota de classificação geral de suas condições de funcionamento.

Diante do exposto, fica claro que no Brasil os estudos e normas sobre inspeção e gerenciamento de OAEs não são suficientemente integrados. Não há um número exato de estruturas existentes e ao menos a quem estas estruturas de fato pertencem. Nestas condições, não há como afirmar a quem de fato cabe a responsabilidade do monitoramento de OAEs. E ainda, se a estrutura vem sendo avaliada de forma qualitativa e não quantitativa.

Conforme NBR 6118 (2014), estados limites são ocasionados por vibração excessiva e são verificados quanto à frequência considerada crítica ou pela fadiga dos materiais. Este fenômeno associa-se as ações dinâmicas repetidas que ativam o processo de modificações progressivas e permanentes da estrutura interna de um material.

A manutenção da estrutura tornou-se essencial, mesmo que o projeto e a obra tenham sido construídos da melhor forma possível. Faz-se necessário que haja um plano de monitoramento contínuo e/ou periódico, de acordo com as grandezas admissíveis de cada estrutura, pois o único modo de evitar catástrofes estruturais ocasionadas por processos de deterioração, desgaste ao uso ou por solicitações naturais são por meios de acompanhamento e manutenção preventiva, para que estes processos de deterioração não se acelerem e se acentuem (Bernasconi, 2011).

A incorporação de métodos de monitoramento no comportamento da estrutura torna-se crescente devido ao alto custo de recuperação de obras. A comunidade científica procura criar sistemas que induzam a sensibilidade às OAEs. Um sistema que seja capaz de informar, instantaneamente, o estado de "saúde" da estrutura e ao mesmo tempo que seja capaz de ajustar o sistema estrutural ao meio ambiente (Figueiredo, 2006).

A tecnologia GNSS, no final da década de 1980, começou a ser utilizada em estudos de caracterização dos deslocamentos dinâmicos de estruturas de grande porte. Graças à sua precisão tridimensional, o GNSS é utilizado em uma ampla variedade de tarefas de monitoramento de movimento em estruturas feitas pelo homem, identificando as variações conforme sua deformação, um exemplo é o monitoramento de barragens de usinas hidrelétricas (Jerke \& Faggion, 2020), (Cruz, et al., 2019) e túneis em rodovias (Yüceses \& Erenoglu, 2019). O GNSS é considerável mais uma ferramenta rentável para tarefa de monitoramento, sendo capaz de satisfazer os rigorosos requisitos de precisão (1,0 a 0,1 ppm) com uma variedade de receptores GNSS que podem ser instalados permanentemente em locais apropriados e controlados remotamente (Wells, et al., 1999).

De acordo com Seeber (2003), para atender aos requisitos de precisão dos dados em tempo real, cientistas e engenheiros desenvolveram o diferencial de fase portadora em tempo real, mais conhecido como RTK (Real Time Kinematic). A maioria das aplicações requer dados em tempo real com a precisão do posicionamento na escala de milímetros para decímetros, podendo então se beneficiar com o uso desta técnica (Langley, 1998). Neste contexto, com a técnica RTK, as correções dos sinais dos satélites GNSS (Global Navigation Satellite Systems) são transmitidas em tempo real, da estação de referência para uma estação a qual se deseja determinar as coordenadas. Estas correções podem ser transmitidas via rádio UHF 
(Ultra High Frequency) ou por meio da internet via GSM (Global System for Mobile Communications), adequado ao protocolo NTRIP (Costa, et al., 2018).

Com o intuito de desenvolver um sistema de monitoramento estrutural em tempo real para obras viárias, por meio da técnica RTK/NTRIP, o presente estudo abordou duas campanhas distintas com diferentes estações referência, sendo estas a estação SPC1, pertencentes a RBMC-IP (Rede Brasileira de Monitoramento Contínuo dos Sistemas GNSS em Tempo Real), localizada na cidade de Campinas - SP e estação SPLI, pertencente ao CEGAT (Centro Geodésico da Alezi Teodolini), localizada na cidade de Limeira - SP (Centro Geodésico da Alezi Teodolini , 2018). Após coleta, realizou-se a análise dos dados, de forma a garantir o total desempenho do sistema de navegação utilizado. Os dados foram abordados e caracterizados por sua acurácia, disponibilidade, continuidade e integridade, sendo possível garantir ou não a eficiência da aplicação da técnica RTK/NTRIP ao monitoramento estrutural em tempo real.

Com a finalidade de verificar o comportamento estrutural em obras viárias e promover um software de monitoramento estrutural em tempo real, foi desenvolvido o SiGE (Sistema de Gerenciamento Estrutural), coletando de forma instantânea as observações GNSS e identificando o quanto a estrutura variou nas componentes planimétricas N (Y), E (X) e na componente altimétrica $\mathrm{h}(\mathrm{Z})$. Com a obtenção destes dados em tempo real e com a implantação do sistema de alerta posicional online, torna-se possível ao gestor ou a equipe técnica avaliar a segurança da estrutura em serviço de forma contínua e promissora, avaliar a segurança do tráfego e, com isso, a redução do número de acidentes envolvendo obras civis.

Atualmente as inspeções Cadastrais e Rotineiras em OAEs são basicamente desempenhadas em inspeções visuais realizadas por técnicos in loco. Devido a isto, as conclusões referentes ao diagnóstico inicial da estrutura bem como sua classificação nos aspectos de segurança estrutural, funcionalidade e durabilidade estão embasadas em uma caracterização rudimentar e pessoal.

Embora o sistema GNSS apresente características únicas, ou seja, restrições ao monitoramento em pontes de concreto armado, Larocca, et al., (2015) e Araújo Neto (2017) propõem o monitoramento GNSS como uma ferramenta capaz de auxiliar, de forma integrada, os instrumentos e as técnicas tradicionais já existentes. Hoje, as inspeções Especiais e Extraordinárias contam com equipamentos auxiliares no processo de identificação de futuras anomalias como pacômetro, sensores e ultrassons (geotécnicos e estruturais) e até mesmo drones na identificação de anomalias de difícil acesso.

A ferramenta GNSS integraria perfeitamente aos equipamentos utilizados nas inspeções Cadastral, Rotineira e até mesmo na Inspeção Especial atendendo aos requisitos de: Localização das estruturas, cadastramentos das estruturas monitoradas; Identificação do comportamento funcional da estrutura em serviço (sendo este uma ferramenta não destrutiva); Monitoramento estrutural em tempo real, (podendo auxiliar inclusive no controle de tráfegos sobre OAEs); Armazenamento dos dados monitorados (em rede e na web) e, por fim, a inclusão de um sistema de alerta posicional com cominação online.

\section{Metodologia}

O estudo foi realizado na Unicamp/FEC (Universidade Estadual de Campinas/Faculdade de Engenharia Civil, Arquitetura e Urbanismo), localizada a rua Saturnino de Brito, 224. Mais precisamente, no DGT (Departamento de Geotecnia e Transporte) na estrutura da caixa d'água (ao lado do DGT), onde também se encontra a estação da RBMC-SPC1. O SME foi instalado ao lado da estação referência SPC1, com distância de 5,95 metros entre as bases.

A estrutura da caixa d'água foi construída em concreto armado e alvenaria de vedação, caracterizada como uma estrutura estável, fixa e segura. Por se tratar de uma estrutura com 9,45 metros de altura, esta favoreceu as observações GNSS. O local tornou-se favorável por não contar com os efeitos de multicaminhamentos, com uma área livre de obstáculos naturais e artificiais. 
Para facilitar o manuseio do receptor GNSS na estrutura, utilizou-se um acessório chamado "adaptador V" de nível a laser. Este adaptador possui um parafuso de fixação para instalação da base nivelante. Os movimentos horizontais são ocasionados por um carrinho com parafusos de fixação em suas extremidades. Os movimentos verticais são ocasionados por uma barra graduada e dois parafusos de travamento. Este equipamento foi fixado na estrutura da caixa d'água de forma a garantir somente os movimentos impostos ao SME, conforme ilustrado pela Figura 1.

Figura 1 - (a) Movimento horizontal imposto ao SME. (b) Movimento vertical imposto ao SME.

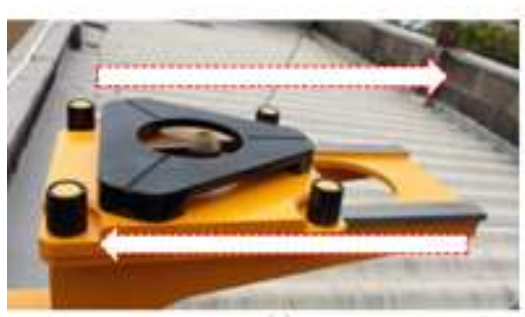

(a)

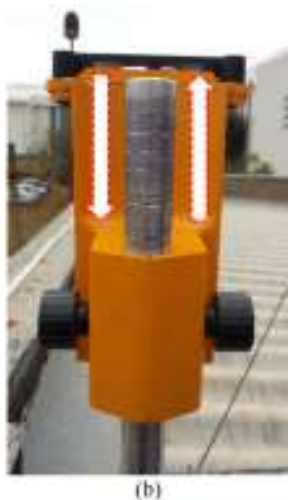

(b)

Fonte: Autores.

A base niveladora utilizada nas medições foi a base nivelante com prumo ótico $A J 12-D$ da, fabricante Xpex. O uso da base garantiu o nivelamento do equipamento na estrutura e a fixação do pino de centragem forçada.

O pino de centragem forçada fixo na base nivelante foi adaptado, conforme Figura 2, uma vez que o receptor necessitaria de trocas de baterias, manuseio dos cabos USB (Universal Serial Bus) e do cabo de energia. O receptor instalado diretamente na base niveladora impossibilitaria a abertura do compartimento das baterias e, com isso, interromperia o monitoramento contínuo em tempo real.

Figura 2 - (a) Receptor instalado na base nivelante. (b) Adequação do pino de centragem forçada da base nivelante ao receptor.

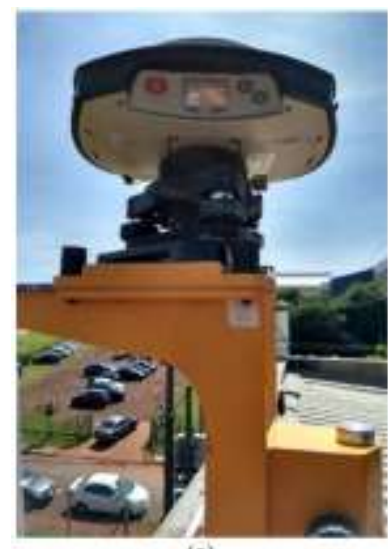

(a)

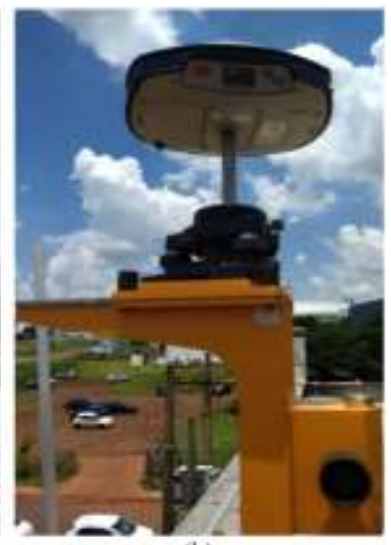

(b)

Fonte: Autores.

Para coleta dos dados, utilizou-se o equipamento GNSS SP80 da Spectra Precision, com comunicação GSM, para operações com técnica $R T K$ e a correção em tempo real via protocolo NTRIP (Spectra, 2016)Este equipamento possui precisão 
para técnica $R T K / N T R I P$ de $8 \mathrm{~mm}+0.5 \mathrm{ppm}$ na horizontal e $15 \mathrm{~mm}+0.5 \mathrm{ppm}$ na vertical, conforme descrito pelo manual de especificações técnicas.

Por se tratar de um monitoramento em tempo real, utilizou-se diferentes linhas de base, a fim de identificar a acurácia, a continuidade, a disponibilidade e a integridade do método. Utilizou-se como estações referências as estações SPC1, pertencente a RBMC-IP (IBGE, 2017), situada em Campinas e a SPLI pertencente a empresa Alezi Teodolini, situada na cidade de Limeira, ambas no estado de São Paulo. O relatório com as informações das estações SPC1 e SPLI.

As campanhas para a coleta de dados ocorreram nos períodos de 13/12/17 a 12/01/18 (primeira campanha) e 01/08/18 a 12/09/18 (segunda campanha). Ao conduzir os experimentos, configurou-se o receptor SP80 para uma máscara de elevação de $10^{\circ}$ e 5 segundos de intervalo de gravação, recebendo as coordenadas corrigidas e as enviando ao SiGE por meio da codificação NMEA (National Marine Electronics Association) via comunicação serial.

Basicamente, a comunicação NTRIP funcionou da seguinte forma: o receptor SP80 estabeleceu uma comunicação via GSM com a estação de referência estabelecida (SPC1 ou SPLI). A estação referência, por sua vez, enviou as observáveis ao receptor, que de forma instantânea, encaminhou ao SiGE os dados GNSS já corrigidos, juntamente com as demais sentenças via codificação NMEA. As demais sentenças foram: data, horário, número de satélites em vista e número de satélites ativos. Todas essas sentenças foram selecionadas pelo receptor por meio da coletora. Todo conteúdo selecionado é enviado ao SiGE pela comunicação serial. O SiGE então é a ferramenta responsável por recolher a série de dados e disponibilizar as informações de forma automática ao usuário.

\subsection{SIGE - Sistema de Gerenciamento Estrutural}

Para identificar o comportamento da estrutura em tempo real, por meio das observações obtidas pela técnica RTK/NTRIP, necessitaria de um software que fosse capaz de demonstrar claramente as variações da estrutura a cada coordenada recebida, identificando instantaneamente os movimentos na componente horizontal $\mathrm{N}(\mathrm{X}), \mathrm{E}(\mathrm{Y})$ e na componente vertical h (Z). Pensando neste conceito, o sistema SiGE foi desenvolvido e implementado em linguagem de programação Delphi7, com o armazenamento dos dados em MySQL (My Structured Query Language).

A Ashtech, fabricante do equipamento Spectra SP80 disponibiliza os formatos aprovados da sentença NMEA, sendo que os utilizados pela leitura do SiGE são: GGA (Global Positioning System Fix Data); GLL (Geographic Position Latitude/Longitude); ZDA (Time \& Date); GSV (Satellites in view) e GSA (GPS DOP and active satellites) (THE NMEA, 2001).

Através da comunicação serial do receptor GNSS com o SiGE, uma série de dados são coletados a cada 5 segundos (programado pelo receptor). As coordenadas geodésicas $(\varphi, \lambda)$ juntamente com data e horário são armazenadas pelo sistema, porém, para facilitar e se compreender os deslocamentos obtidos, estas coordenadas são transformadas em coordenadas planas retangulares UTM (Universal Transversa de Mercator). Para isto, as coordenadas geodésicas em graus decimais, foram convertidas para grau, minuto e segundo, e por fim, em coordenadas UTM (em metros). Todo referencial utilizado nas medições, inclusive pelo SiGE, está embasado no sistema geodésico de referência SIRGAS2000 (Sistema de Referência Geocêntrico para as Américas).

Outro aspecto abordado foi a opção de análise dos dados em coordenadas topográficas locais. As coordenadas planoretangulares (X, Y) que serão apresentadas no sistema topográfico local arbitrário são obtidas a partir de suas coordenadas geodésicas transmitidas pelo receptor $(\varphi, \lambda)$ e das coordenadas geodésicas da origem do sistema. Às coordenadas planoretangulares da origem do sistema topográfico local arbitrário (neste estudo, considerou-se como arbitraria a Estação SPC1) são adicionados os termos constantes 150000,000 metros e 250000,000 metros, respectivamente, para a abscissa (X) e para a ordenada (Y), no escopo de evitarem-se valores negativos nos demais pontos da área de abrangência do sistema. Torna-se 
válido ressaltar que a origem do sistema topográfico local deve estar posicionada, geograficamente, de modo que nenhuma coordenada plano-retangular tenha valor superior a $50 \mathrm{~km}$, conforme descritas pela NBR 14166 (Associação Brasileira de Normas Técnicas, 1998).

Para efeito de validação dos dados convertidos pelo SiGE, as conversões das coordenadas geodésicas para coordenadas UTM foram verificados através da calculadora geográfica online disponível pelo INPE (Instituto Nacional de Pesquisas Espaciais). Para efeitos de validação das coordenadas geodésicas para coordenadas topográficas locais obtidas pelo receptor GNSS, realizou-se um levantamento topográfico na área de estudo com a utilização de uma Estação Total da fabricante Leica, modelo TC305 (Leica, 2012).

Embora o segmento GNSS tenha algumas peculiaridades quanto a integridade do posicionamento, parte-se daí a ideia de inserir um sistema de alarme posicional ao SiGE. O alerta será enviado por mensagem via aplicativo Telegram e via e-mail solicitando aos operadores que verificarem a disponibilidade do sinal GNSS e a descontinuidade do sinal de comunicação com a estação referência. Após a comunicação reestabelecida é possível identificar se a estrutura está realmente se deslocando. Basicamente, o sistema de alarme posicional é baseado em função dos dados obtidos em todas as campanhas de coleta. Trabalhou-se em uma modelagem em função da continuidade dos dados.

\section{Resultados e Discussão}

Logo na primeira campanha, com o intuito de identificar a acurácia das estações referências SPLI e SPC1, foram coletados os dados de forma contínua, em ambas as estações, conforme, a fim de identificar a variação máxima (erro medido) a partir do ponto referência $(0)$.

Com a análise dos dados da primeira campanha foi possível identificar que devido a distância entre linha de base e o ponto monitorado, os dados obtidos pela estação referência SPLI do CEGAT, situada na cidade de Limeira - SP, não apontaram uma boa acurácia para a aplicação de um sistema de monitoramento estrutural contínuo em tempo real, tendo como maior fator de erro a descontinuidade dos dados. Sendo assim, a segunda campanha destinou-se apenas a coleta de dados com a estação referência SPC1.

Contudo, para melhor análise, a Tabela 1Erro! Fonte de referência não encontrada. apresenta os valores correspondentes ao erro de medição (variação máxima), valor médio e seu respectivo erro sistemático, pelo método RTK/NTRIP.

Tabela 1 - Análise da acurácia do método RTK/NTRIP.

\begin{tabular}{|c|c|c|c|c|c|c|c|c|c|c|}
\hline Estação Base & Estação Coletora & Erro & de mediçấ & $(\mathbf{m})$ & Méd & a dos erro & (m) & Erro & sistemátic & (m) \\
\hline \multirow{2}{*}{ SPC1 } & \multirow{2}{*}{ SP80 } & $\mathrm{N}$ & $\mathrm{E}$ & $\mathrm{h}$ & $\mathrm{N}$ & $\mathrm{E}$ & $\mathrm{h}$ & $\mathrm{N}$ & $\mathrm{E}$ & $\mathrm{h}$ \\
\hline & & 0,00731 & 0,01800 & 0,01700 & $-0,00166$ & $-0,00407$ & 0,00145 & $-0,00897$ & $-0,02206$ & $-0,0155$ \\
\hline
\end{tabular}

Fonte: Autores.

Diante dos erros obtidos, é possível considerá-los como uma variação máxima aceitável (inserida no cadastro da obra a ser monitorada), pois esta variação está diretamente relacionada à precisão da técnica RTK/NTRIP. A variação máxima aceitável ajudará no que se refere ao limite de alarme (LA) para solucionar os erros já descritos pela continuidade dos dados em tempo real e com isto, serão aplicados ao sistema de alerta posicional. 


\subsection{Disponibilidade}

Em virtude da disponibilidade, foi inserido ao SiGE (Figura 3) a coluna "número de satélites" por meio do código NMEA GSA, registrando o número de satélites que estão realmente se comunicando com o receptor, sendo que na tela do receptor está identificado o número de satélites em vista.

Figura 3 - Coluna número de satélites inseridas ao SiGE.

\begin{tabular}{|c|c|c|c|c|c|c|c|c|c|}
\hline \multicolumn{10}{|c|}{ RBIATORIOS } \\
\hline & iD & Data e Bora & & Variacas Ifini & Varibcac E $(\mathrm{n})$ & Vartaceo $\mathrm{h}(\mathrm{m})$ & Slo.Sat & & \multirow[t]{12}{*}{ A } \\
\hline b) & 2sisech & $18 / 08 / 2018$ & $02: 46: 0$ & 0. as7ad & $-0,00991$ & $-0,080$ & & 15 & \\
\hline & 253650 & $28 / 00 / 2018$ & $02+46: 1$ & 0) 01699 & -4.01009 & $-0,085$ & & 15 & \\
\hline & 253651 & $18 / 08 / 2018$ & $02: 46: 2$ & B. 4845 & $-0,00513$ & $-0,053$ & & 15 & \\
\hline & 253652 & $10 / 00 / 2010$ & $02 \div 46+2$ & D, oines & $-0,00695$ & $-0,003$ & & 15 & \\
\hline & 253653 & $18 / 08 / 2019$ & $02: 46: 2$ & B.01113 & $-0,008 E 1$ & $-0,0 \equiv E$ & & 15 & \\
\hline & 253es4 & $15 / 00 / 2010$ & $02: 46: 3$ & B.otors & $-0,00693$ & $-0,081$ & & 15 & \\
\hline & 253655 & $18 / 00 / 2019$ & $02: 46: 3$ & 0.91212 & $-0,00863$ & $-0,085$ & & 15 & \\
\hline & 253656 & $18 / 00 / 2018$ & $02+46 \div 4$ & e, atoses & $-0,00011$ & $-0,0 \pm t$ & & 15 & \\
\hline & 253657 & $28 / 08 / 2019$ & $02 \pm 46: 4$ & D,01704 & $-0,00777$ & $-0,013$ & & 15 & \\
\hline & 253650 & $10 / 00 / 2010$ & $02 t 46: 5$ & 0,01609 & -0.00940 & $-0,004$ & & is & \\
\hline & 253659 & $18 / 00 / 2019$ & $02146: 5$ & 0.01ney & $-0,00865$ & $-0,075$ & & is & \\
\hline
\end{tabular}

Fonte: Autores.

A não disponibilidade é considerada quando o número de satélites é inferior a 5 para um intervalo superior a 10 segundos. O receptor SP80 obteve de 15 a 20 satélites, considerando-se uma boa disponibilidade. No entanto, para o posicionamento RTK/NTRIP são necessários que outros sistemas também estejam disponíveis. Dentre eles pode-se citar o acesso à rede de telefonia celular que o usuário utiliza para realizar a comunicação com a estação referência de forma contínua. Outro fator importante tem a ver com a disponibilidade de cada estação de referência a ser utilizada. Ao todo são 104 estações disponibilizadas pela RMBC-IP e 27 disponibilizadas pelo CEGAT.

\subsection{Continuidade}

Por se tratar de um monitoramento contínuo em tempo real, o SiGE consegue identificar falhas ocorridas pela descontinuidade de forma instantânea. Neste caso, só houve a continuidade dos dados quando a comunicação com a base foi restabelecida (pela coletora), comunicando-se novamente a estação referência. A perda se sinal resultou a variações métricas, achegando a 3,0 metros na componente $\mathrm{N}$, a 3,3 metros na componente $\mathrm{E}$, e a 6,3 metros na componente $\mathrm{h}$.

A falha na comunicação pode ser ocasionada pela limitação de acesso à base referência ou uma falha na comunicação GSM, pois ao reestabelecer a comunicação com a base, os dados retornam instantaneamente para o mesmo nível de precisão. Quando não há possibilidade de comunicação com a base, a coleta não é iniciada, forçando o operador a escolher uma outra estação referência mais próxima.

Houve também dois períodos de instabilidade de dados. Propositalmente, não houve intervenção na comunicação (via coletora), sendo possível identificar o período para que o sinal fosse restabelecido, ou seja, a continuidade na coleta de dados. A instabilidade dos dados resultou a variações métricas, achegando a 0,8 metros na componente $\mathrm{N}, 1,3$ metros na componente E 1,2 metros na componente $h$.

O período temporal de instabilidade dos dados fora igual para todas as componentes. O primeiro período ocorreu entre 14:35:00 e 14:59:00 (hora:minuto:segundo), totalizando 00:24:00 de descontinuidade. O segundo período ocorreu entre 
15:48:00 e 16:22:00, totalizando 01:22:00. Este período de instabilidade dos dados pode ser caracterizado como uma variação GNSS ou uma falha na comunicação GSM.

\subsection{Integridade}

Em virtude dos dados obtidos, o SiGE trabalhará de forma instantânea aos sinais de continuidade. Uma modelagem do sistema considera o fator tempo (podendo este ser alterado) bem como um período de instabilidade de sinal. Sem a continuidade de sinal, os dados terão uma discrepância nos valores obtidos (dados com alto erro de medição). Com a descontinuidade, a coloração dos dados mudará atentando ao técnico que houve uma descontinuidade no sinal.

Com o aviso de alteração nos dados, os técnicos cadastrados poderão verificar se está havendo um processo de descontinuidade de sinal (GNSS ou GSM) ou se realmente a estrutura em monitoramento esteja sofrendo um processo de deslocando anormal. Após análise de dados, foi possível identificar uma média do período de instabilidade dos dados sem a necessidade de restabelecer a comunicação com a estação referência. Por conta do período instabilidade de dados e os picos derivados de erros de medição, o alerta terá uma variável tempo, onde somente após 30 minutos de dados instáveis o alerta será acionado. Desta forma, o fluxograma (Figura 4) descreve como o sistema de alerta trabalhará para que o alarme seja eficiente no que diz respeito a integridade na coleta de dados.

Figura 4 - Fluxograma do processamento do sistema de alerta posicional do SiGE.

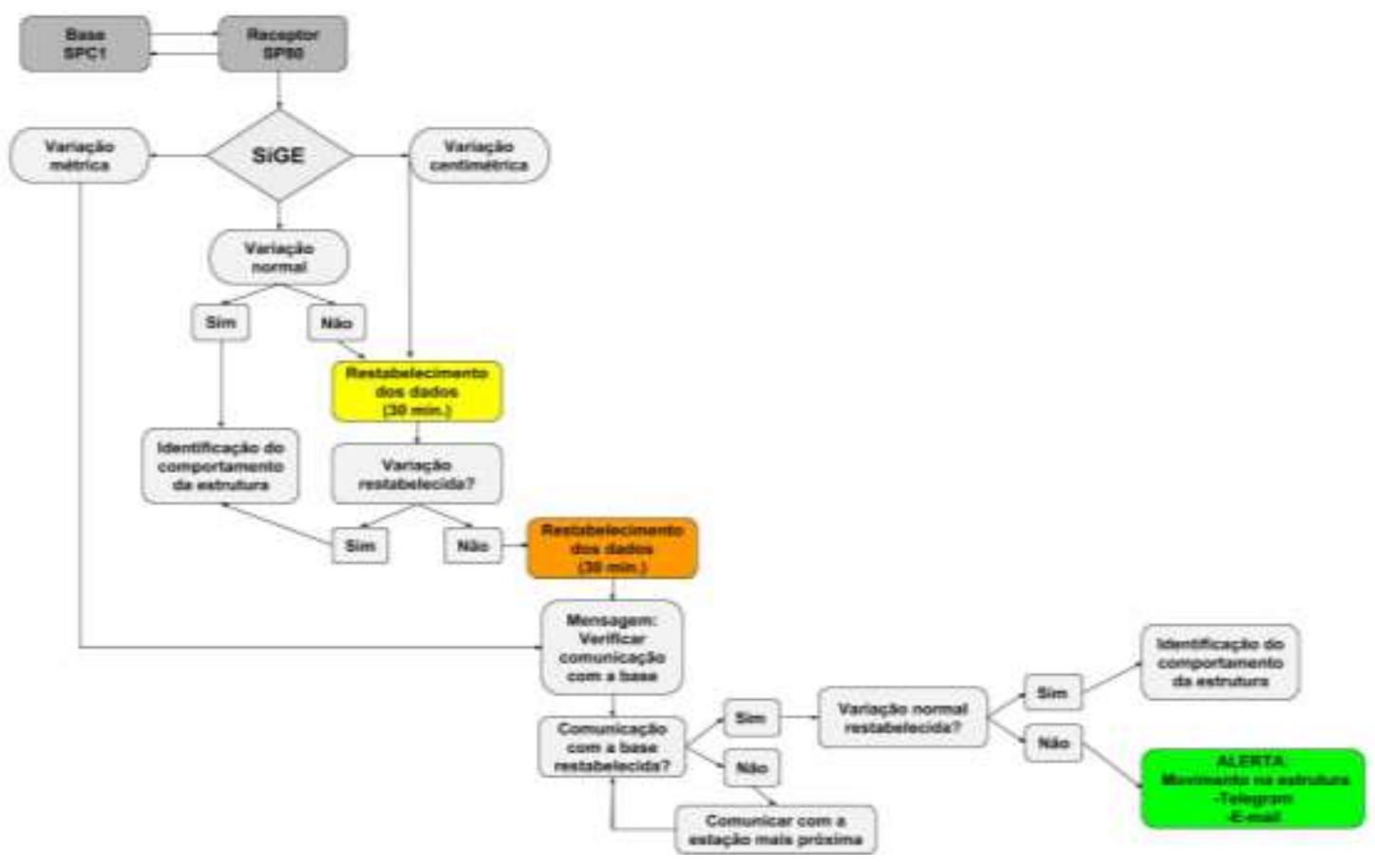

Fonte: Autores.

Os estudos referentes aos deslocamentos impostos ao SME destinaram-se a identificação de movimentos milimétricos e se era possível identificar tais deslocamentos. Os deslocamentos partiram do ponto referência " 0 " até o deslocamento de 26 $\mathrm{mm}$. Os deslocamentos na componente horizontal ocorreram em um único sentindo, fazendo com que a componente $\mathrm{N}$ demonstrasse os valores dos deslocamentos impostos ao SME.

Para melhor compreensão e convalidação dos dados, realizou-se o pós-processamento pelo software RTKLib no modo cinemático. Abaixo, as Figura 5 e 6 e demostram o comportamento pelo Pós-Processado Cinemático e pelo método RTK/NTRIP, em diferentes pontos do SME. 
Research, Society and Development, v. 10, n. 8, e3410816846, 2021

(CC BY 4.0) | ISSN 2525-3409 | DOI: http://dx.doi.org/10.33448/rsd-v10i8.16846

Figura 5 - SME no ponto 3 mm. (a) Pós-Processado Cinemático. (b) RTK/NTRIP.
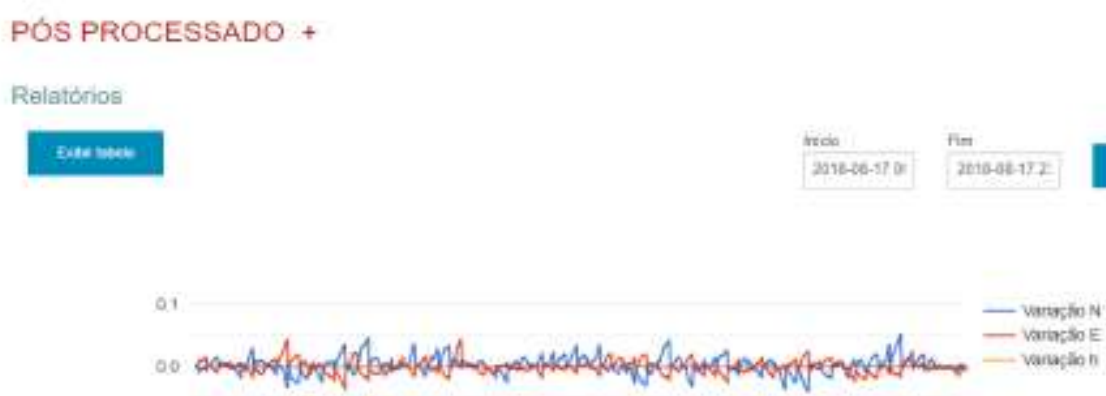

(a)

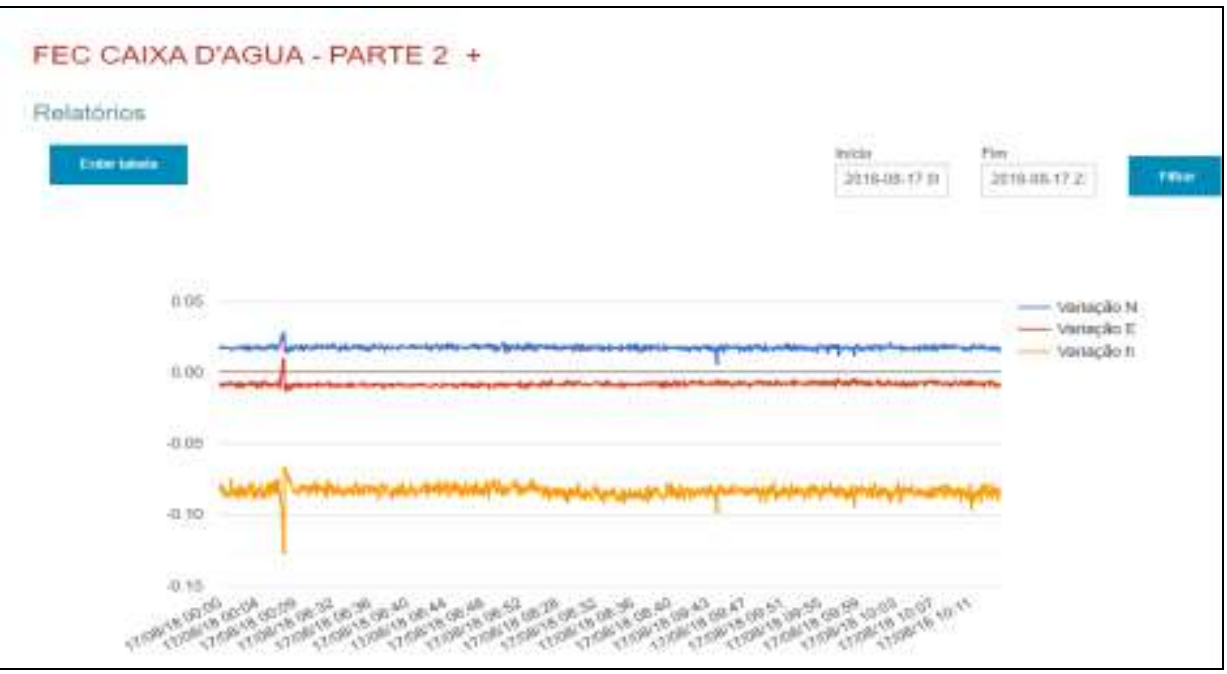

(b)

Fonte: Autores. 
Figura 6 - SME no ponto 8 mm. (a) Pós-Processado Cinemático. (b) RTK/NTRIP.

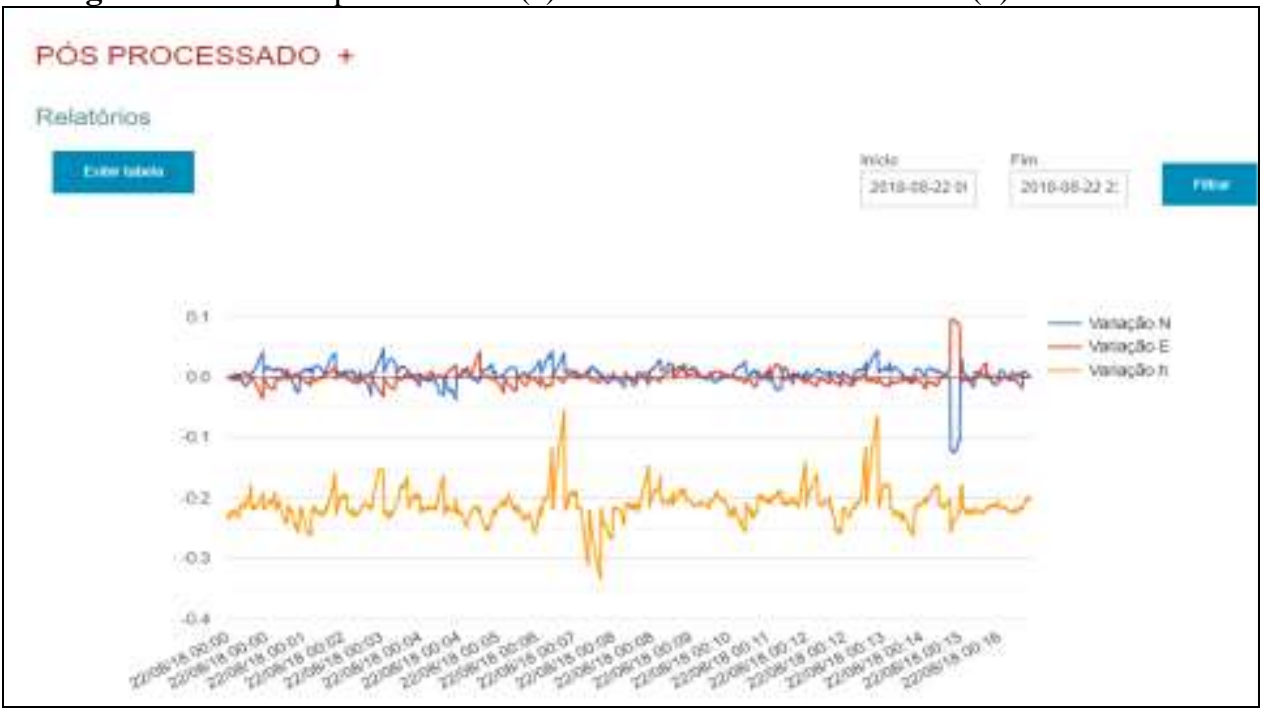

(a)

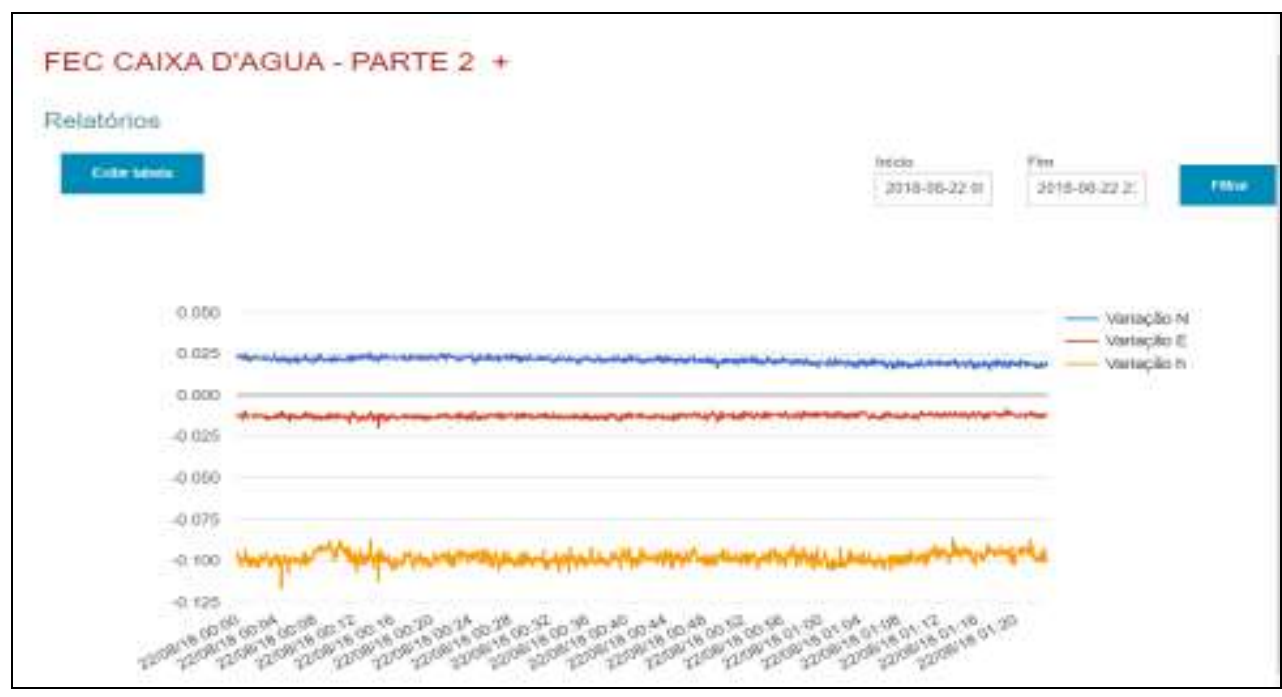

(b)

Fonte: Autores.

Para garantir uma melhor análise dos dados, abaixo segue a

Tabela 2 contendo os valores máximos e mínimos, juntamente com suas respectivas amplitudes, obtidos pelo pósprocessamento cinemático e pela técnica $R T K / N T R I P$.

Tabela 2 - Análise dos dados pós-processados cinemático e RTK/NTRIP.

\begin{tabular}{|c|c|c|c|c|c|c|c|c|c|c|c|c|}
\hline \multirow{3}{*}{$\begin{array}{l}\text { Ponto } \\
(\mathrm{mm})\end{array}$} & \multicolumn{6}{|c|}{ Pós-Processamento Cinemático } & \multicolumn{6}{|c|}{ RTK/NTRIP } \\
\hline & \multicolumn{3}{|c|}{$\mathbf{N}(\mathbf{m})$} & \multicolumn{3}{|c|}{$\mathbf{h}(\mathbf{m})$} & \multicolumn{3}{|c|}{$\mathbf{N}(\mathbf{m})$} & \multicolumn{3}{|c|}{$\mathbf{h}(\mathbf{m})$} \\
\hline & Máx. & Min. & Ampl. & Máx. & Min. & Ampl. & Máx. & Min. & Ampl. & Máx. & Min. & Ampl. \\
\hline 3 & 0,077 & $-0,085$ & 0,162 & 0,010 & $-0,381$ & 0,391 & 0,061 & $-0,013$ & 0,074 & 0,499 & $-0,060$ & 0,559 \\
\hline 8 & 0,087 & $-1,339$ & 1,426 & 8,661 & $-0,475$ & 9,136 & 0,135 & $-0,472$ & 0,607 & 0,549 & $-0,599$ & 1,148 \\
\hline
\end{tabular}

Fonte: Autores.

O pós-processamento de dados é bastante comum em casos em que não há a necessidade de adquirir as posições dos pontos em tempo real. Algumas tarefas, no entanto, exigem posicionamento em tempo real, como no caso do estudo do 
comportamento de uma estrutura. A precisão necessária da posição (ou aceitável) depende muito da aplicação. Neste contexto, o posicionamento RTK/NTRIP se manteve mais íntegro em comparação ao pós-processamento cinemático em se tratando do comportamento em tempo real de uma estrutura.

Desconsiderando os picos (falhas GNSS), foi possível identificar que o movimento imposto ao simulador em movimentos milimétricos de 3 a 8 milímetros, obtiveram o mesmo comportamento. Isso implica que para detecção de movimentos estruturais, ou seja, na identificação do comportamento da estrutura, deverá ser abordado uma escala decimétrica/centimétrica, tornando-se aplicáveis a estruturas em balanço, pontes estaiadas e OAEs com grandes vãos.

\section{Considerações Finais}

Os resultados mostraram-se promissores dentro da análise da acurácia, disponibilidade, continuidade e integridade dos dados obtidos pelo método RTK/NTRIP.

As variações máximas ou erros obtidos ficaram na escala milimétrica/centimétrica nas componentes $\mathrm{N}(\mathrm{X}), \mathrm{E}(\mathrm{Y})$ e $h(Z)$, provando uma boa acurácia, pois quanto menor a variação do erro, maior a probabilidade de identificação do comportamento anormal da estrutura monitorada.

As condições favoráveis do receptor resultaram em uma excelente disponibilidade, tendo em média a comunicação com 15 a 25 satélites. As condições também foram favoráveis a comunicação GSM devido à localização urbana da área de estudo e pela estreita linha de base à estação referência SPC1. Embora não haja cobertura suficiente em todo território brasileiro para estudos em áreas sem sinal de telefonia, recomenda-se a utilização pelo método RTK/UHF.

A continuidade teve como maior fator de erro as "falhas de comunicação", sendo estas impossíveis de serem afirmadas como uma falha da estação referência (como limitações de usuários ou uma eventual queda de energia) ou uma falha na ligação GSM do receptor com a estação referência. Para ambos os casos, a solução é restabelecer a comunicação do receptor com a estação referência, ou seja, o sistema deve ser reiniciado pela coletora. Desta forma, foi possível identificar que estas falhas podem ser solucionadas por meio do sistema de alerta posicional, peça chave do SiGE, mantendo-se assim a integridade GNSS.

A integridade corresponde diretamente à visualização dos dados e o comportamento da estrutura monitorada em tempo real. O sistema de alarme trabalhará de fato com a possível falha na comunicação "receptor x estação referência" ou em um movimento anormal na estrutura.

O monitoramento em tempo real pela técnica RTK/NTRIP torna-se viável a diversas áreas do monitoramento viário, como encostas com riscos de deslizamentos, linhas de proteção natural em desnível e em OAEs no controle de cargas, sendo estes fatores importantes a serem abordados no processo de inspeções Cadastrais e Rotineiras em OAEs, descritos pela NBR 9452.

Atualmente, estruturas viárias podem ser classificadas em dois tipos: Estruturas antigas (construídas em meados à década de 1960); e as estruturas novas (contemplando as obras mais atuais, na maioria sem qualidade na execução). Por isso, torna-se indispensável aos órgãos responsáveis a manutenção destas estruturas e que tenham no mínimo as inspeções cadastrais e rotineiras de forma atualizada, pois só assim será possível evitar eventuais acidentes irreversíveis à estrutura.

De forma geral, o SiGE tornou-se uma ferramenta eficiente e eficaz no que diz respeito a utilização do método de posicionamento relativo em tempo real e na identificação do comportamento de forma clara e ilustrativa. Sua utilização contempla a visualização gráfica do comportamento da estrutura, a organização dos dados monitorados, emissão de relatórios instantâneos, identificação do ponto a ser monitorado, utilização de diferentes sistemas de coordenadas (UTM e Topográfica local) e, principalmente, a introdução do sistema de alerta online com a comunicação entre o SiGE e aos usuários cadastrados, fazendo do SiGE um software de grande utilidade no que diz respeito ao planejamento, controle e inspeção estruturas de obras 
viárias.

Em relação aos trabalhos futuros que englobem a temática do monitoramento estrutural de OEAs, sugere-se o emprego do SiGE afim de corroborar com a validação do software por outros usuários. Outro ponto importante a ser abordado é a praticidade em se obter informações da estrutura monitorada. A equipe técnica cadastrada terá acesso à página do SiGE, contendo todas as informações necessárias aos monitoramentos já registrados e ao comportamento da estrutura em tempo real.

\section{Referências}

Associação Brasileira De Normas Técnicas. (1998). NBR 14166: Rede de Referência Cadastral Municipal - Procedimento. ABNT.

Associação Brasileira De Normas Técnicas. (2004). NBR 6118: Projeto de estruturas de concreto - Procedimento. ABNT.

Associação Brasileira De Normas Técnicas. (2016). NBR 9452: Inspeção de Pontes, Viadutos e Passarelas de Concreto - Procedimento. ABNT.

Araújo Neto, J. O. (2017). Uso do GPS no monitoramento dinâmico da infraestrutura de transportes: Pontes rodoviárias em concreto. Unicamp.

Bernasconi, J. R. (2011). Editorial. Infraestrutura - O Brasil não tem cultura de realizar manutenção em obras. http://piniweb.pini.com.br/construcao/infraestrutura/brasil-nao-tem-cultura-de-realizar-manutencao-em-obras-afirma-242228-1.aspx

Centro Geodésico da Alezi Teodolini . (2018). CEGAT. Futuro do posicinamento. Alezi Teodolini.

Costa, S. M. A., Lima, M. A. A., Junior, N. J. M., Abreu, M. A., Silva, A. L., \& Fortes, L. P. S. (2018). Artigos em Geodésia. RBMC em tempo real, via NTRIP, e seus benefícios nos levantamentos RTK e DGPS. https://artigos.ibge.gov.br/artigos-home/geodesia/2008-2005/3067-rbmc-em-tempo-real-via-ntrip-eseus-beneficios-nos-levantamentos-rtk-e-dgps.

Cruz, W., Faggion, P. L., \& Muggio, M. R. (2019). Análise dos resultados de processamentos de dados GNSS aplicado ao monitoramento de estruturas, utilizando efemérides transmitidas, precisas e o Posicionamento por Ponto Preciso do IBGE. Revista Brasileira de Geomática, 7 (1), $61-79$.

Departamento Nacional de Insfraestrutura e Transporte. (2004). Manual de inspeção de pontes rodoviárias. DNIT.

Departamento Nacional de Insfraestrutura e Transporte. (2010). Manual de Projeto e Práticas Operacionais para Segurança nas Rodovias. DNIT.

Departamento Nacional de Insfraestrutura e Transporte. (2010). Manual de recuperação de pontes e viadutos rodoviários. DNIT.

Departamento Nacional de Insfraestrutura e Transporte. (2016). Manual de Manutenção de Obras de Arte Especiais - OAEs. : DNIT.

Departamento Nacional de Insfraestrutura e Transporte. (2015). Seção Notícias. Pontes e viadutos das rodovias federais estão em boas condições. http://www.dnit.gov.br/noticias/pontes-e-viadutos-das-rodovias-federais-estao-em-boas-condicoes.

Figueiredo, E. J. F. (2006). Monitorização e avaliação do comportamento de obras de arte. Universidade do Porto.

Instituto Brasileiro de Geografia e Estatística. (2017). RBMC-IP, Rede Brasileira de Monitoramento Contínuo dos Sistemas GNSS em tempo real. IBGE.

Jerke, A., \& Faggion, P. L. (2020). Análise do Monitoramento Geodésico de barragem com Equipamentos de Diferentes Precisões e Diferentes Softwares de Processamento. Anuário do Instituto de Geociências, 43 (4), 310-318. dx.doi.org/10.11137/2020_4_310_318.

Langley, R. B. (1998). RTK GPS. Fredericton, Canada: University of New Brunswick.

Larocca, A. P. C., Araújo Neto, J. O., Trabanco, J. L. A., Barbosa, A. C. B., Cunha, A. L. B. N., \& Schaal, R. E. (2015). Uso de Receptores GPS de 100 hz na Detecção de Deflexões Verticais Milimétricas de Pontes de Concreto de Pequeno Porte. Boletim de Ciências Geodésicas, , 21 (2), 290-307. doi.org/10.1590/S1982-21702015000200017.

Leica. (2012). Leica Viva GNSS Receptor GS15. Leica Geosystems.

Seeber, G. (2003). Satellite Geodesy: fundations, methods and applications. De Gruyter.

Spectra. (2016). Manual de especificações técnicas receptor GNSS SP80. Spectra Geospatial.

Tribunal de Contas da União. (2012). Relatório TC 009.746/2012-9 ao Departamento Nacional de Infraestrutura de Transportes. TCU.

National Marine Electronics Association. (2001). THE NMEA 0183 Protocol. Severna Park, Estados Unido da América: NMEA.

Timerman, J. (2018). Inspeção de Pontes - O estágio atual da normalização. IBRACON.

Wells, D., Beck, N., Delikaraoglou, D., Kleusberg, A. E. J., Lachapelle, G., Langley, R. B., Nakiboglu, M., Schwarz, K. P., Tranquilla, J. M., \& Vanicek, P. (1999). Guide To Gps Positioning. University of New Brunswick.

Yüceses, O., \& Erenoglu, R. C. (2019). Deformation Analysis by Geomatic and Geotechnical Methods in Highway Tunnels. International Journal of Environment and Geoinformatics, 6 (2), 163-171. dx.doi.org/10.30897/ijegeo.54083. 